\title{
Developing and using multimedia effectively for undergraduate teacher education
}

\author{
Dianne P. Chambers and Kaye Stacey \\ The University of Melbourne
}

\begin{abstract}
Members of the Department of Science and Mathematics Education at the University of Melbourne have developed a range of multimedia resources for undergraduate education students, that allow the students to participate in authentic tasks that would otherwise be difficult or impossible to arrange for large numbers of students. The multimedia resources have been carefully designed to project students into their future role as classroom teachers, as it has been observed that those students who do this tend to perform better, as they can see the relevance of learning opportunities presented in their studies. Observation of student work using these resources shows deeper thinking and enhanced reflective practices in considering how children think.
\end{abstract}

\section{Introduction}

As teacher educators, we often observe that successful teacher education students are those who can project themselves into their future role as a classroom teacher - these students can see the relevance and application of material they are taught and tasks they are set, from very early in their studies. For other students, it is only as they progress through their undergraduate degree and gain more classroom experience that the materials and tasks presented at university appear to increase in relevance to them. Staff at the Department of Science and Mathematics Education at the University of Melbourne have taken up the challenge to help undergraduate students project themselves into their future role as classroom teachers, by developing multimedia resources that set up authentic tasks and scenarios. This paper will discuss the design, uses, and the different modes of interactivity that have been incorporated into the multimedia resources developed for the Bachelor of Education (Primary) course. [The term 'student' is used throughout this paper to mean a student in a teacher education course. The word 'child' will be used to mean a student taught in an elementary school (K-6)] 
The Bachelor of Education (Primary) degree is a four-year course of study and is the principal vehicle for the training of primary (elementary/K-6) teachers at the University of Melbourne. In 1995 the degree was restructured and updated extensively. This restructuring was accompanied by a substantial reassessment of the direction of the course and of the priorities for competing areas, focusing the course more strongly on the professional role. Simultaneously, budget constraints led to larger groups in the university based teaching, and other changes led to a reduction of $20 \%$ in the number of days of supervised practical work in schools ('teaching rounds'), with a shift of responsibility towards the schools. In total, these changes reduced the face to face contact between university staff and students in a teaching context. but also provided opportunities within the course for restructuring university programs around elementary classroom issues. It was therefore an ideal time to invest in revising course delivery in this degree program. Multimedia was selected as one priority because of its potential to make experience with children a well-integrated part of the university course. In the next sections we describe two projects and highlight the ways that we have designed, for students to engage actively with the multimedia and the task.

\section{Computers and the K-6 Classroom: Kids Can Do!}

\section{Description of the resource}

For the compulsory second year undergraduate subject 'Computers in the Primary Classroom' a resource entitled Computers and the K-6 Classroom: Kids Can Do! (Chambers \& Dobbins, 1997) was developed in 1996-97 with version 1 being launched late in 1997 (version 2 was released early 1999). This resource contains lecture notes and workshop activities, over 100 articles about using computers in K-6 classrooms, demonstration versions of software, and examples of teachers' and children's classroom work with computers. These materials (mostly print with some electronic examples) are used in familiar ways within the program. The electronic format makes the material reasonably priced and easily updated, an essential feature for materials in any subject on using information technology.

The most interesting section of this resource is the Virtual Classrooms, which was developed in Macromedia's Director program and contains QuickTime VR with embedded video clips of three classrooms, and interviews with the three classroom teachers (Figure 1). The classroom videos are designed in a different way to many of the multimedia resources for teacher education, which show lessons or lesson segments. For example, one early, commercially available product that we have used with our students is 'Learning about Teaching' (Mousley, Sullivan \& Mousley, 1996). This presents a video of a complete lesson, principally focused on the teacher, 
which is documented and cross-referenced in many helpful ways and which directs students to focus on the actions of the teacher in teaching the lesson. The Virtual Classrooms resource is quite different, presenting instead a snapshot in time of all that is going on in a busy classroom. As our students 'move' around the room (using the virtual reality controls) they can see what each group of children is doing and how the teacher is managing the classroom. At heart, this resource is therefore a collection of presentations of videoclips showing children working in class, which is accessed and indexed spatially rather than through text.

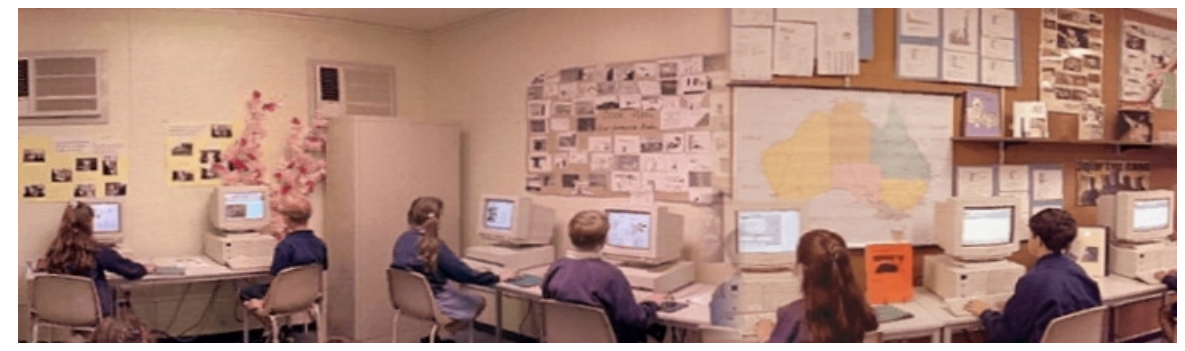

Figure 1: A 'flattened' image from one of the QuickTime VR photographs from the Virtual Classrooms from Computers and the K-6 Classroom: Kids Can Do!

In the Virtual Classrooms our students can explore the classrooms of teachers at three schools. The classrooms and teachers were selected as each is using computers effectively across the curriculum, yet there are major differences in how the computers are used and how they are set up in (and out of) the classrooms. The observation of classrooms and their workings by our students is made considerably easier through the use of multimedia as it allows all students to observe exemplary practice in the uses of computers in the classroom - something not all students have an opportunity of observing during their time in school experience ('teaching rounds') and the same experience is shared by all classmates. In addition, students can visit and revisit the Virtual Classrooms and as their own experience grows, they extract new significance from the interactions they observe.

\section{Key decisions made in design}

The following outlines some of the educational decisions made when designing the Virtual Classrooms part of the Computers and the K-6 Classroom: Kids Can Do! resource. The underlying principle was to expose our students to exemplary ways computers could be used in K-6 classrooms and to further students' understandings of the reasoning behind the choices that exemplary teachers made when using technology to support children's 
learning. Key principles were to demonstrate a range of possibilities for organisation, an exciting array of activities that children could undertake, and to expose the teachers' decision making process.

\section{Features of the resource}

Three Models of Computers in Schools: The resource illustrates three common organisational models: a classroom with two computers; a computer laboratory; and a 'mixed model' of classroom computers plus access to a computer laboratory. As computers in classrooms are still a reasonably new development for many teachers and levels of resources are quite variable between schools, there is not a single leading model of the 'right' way to implement technology in the K-6 classroom. (It is acknowledged that for some teachers a computer has been in their classroom since the 1980s!) The schools our students will be teaching in, and the classrooms they visit as part of their practical experience, may have any of these models in action. Illustrating a range of ways for successfully using computers to support learning was considered to be of greater value to our students than presenting them with a 'preferred model', which may or may not be possible when they arrive as a new teacher. The virtual reality feature enables students to explore the physical layout of the classroom in great detail.

'Talk to the Teacher': An important section of the Virtual Classrooms resource is a series of video clips where each of the three teachers answers questions about what she does with technology in the classroom and the reasons behind the decisions she has made. Making explicit the teachers' reasons for selecting their approaches will, we believe, deepen our students' thinking about using technology in the classroom and, we hope, promote an ongoing attitude of questioning.

Contradictory Views: Each teacher (one teacher is associated with each classroom) has a different view on why their style of using computers works for them and for the children in their classes. The inclusion of a range of, sometimes contradictory, opinions was deliberate so that our students could see that there are many ways of using computers and associated technologies effectively in classrooms. Studying the video clips demonstrates that effective use of computers was dependent not on how many computers or the layout of the computers in the room, but rather how the teacher used the resources and managed their classroom.

\section{Ways it is used: Analysing classroom interactions and management}

Students investigate aspects of the room in a QuickTime VR environment and by clicking on hotspots a video clip of an interaction is played. Our second year teacher education students analyse the classrooms in the 
Virtual Classrooms resource to investigate the classroom interactions (such as, children and the teacher, children working together, children at computer) and identify the key issues in classroom management in using computers effectively that were illustrated in the video clips. Students work in pairs for this activity and they engage in thoughtful discussions. Their responses indicate deep reflection on the set up and activities in the classrooms. Lecturers, including the first author, observed that the level of reflection and focus on the task was greater than during other activities with these students. Below is an example of one second year undergraduate student's response to an aspect of this task. It indicates both detailed observation and identification of the key issues illustrated in one video clip.

The classroom was well set up with different activity tables relating to the same theme. This scene showed how organised the boys were when they had finished their computer task. They immediately went straight to the roster chart, marked it off and checked which activity they had to move to next. It showed them working cooperatively, and they were not distracted as they knew exactly where they had to go next. The roster was placed strategically near the teacher so that she could also keep an eye on who should be where and when. All computers were placed against the back wall, with their wires placed at the back of the tables.

The Virtual Classrooms show 'staged' video clips of children presenting work based on real work done in the classroom of the interviewed teachers, but enriched in various ways by distilling classroom interactions. This enrichment is an important benefit of the design of the resource. Each virtual classroom conveys, in a compact form, a wide variety of activities undertaken by students at various stages of the task that the class was set. Although presented as a snapshot in time, it is richer than at any one moment of a real classroom. Not all of the activities are 'exemplary' - some are selected for discussion purposes. Usually a teacher's attention can focus on only one group at a time, but here the activities of all the students can be observed. The resource therefore enables a rare (although scripted) glimpse into the totality of activity of all the members of a classroom.

\section{Teaching and learning about decimals}

Teaching and Learning about Decimals (Steinle, Stacey \& Chambers, 2002) is a rich resource for practising teachers and education students alike to assist in teaching children about decimal numbers, an area of mathematics that is difficult for many children. This project is an offshoot of a major research project about the learning of decimals by children, Improving learning outcomes in numeracy: Building rich descriptions of children's thinking into a computer based curriculum delivery system, funded by a grant from the Australian Research Council to Kaye Stacey and Elizabeth Sonenberg (see 
Stacey \& Steinle, 1998). It is therefore an example of a strong link between research and teaching, which is so desirable in university education. Mathematics education research is providing knowledge concerning things teachers can expect to see as children learn mathematics, and our resource and others, such as the Professional Development in Chance and Data CD ('CED PD CD' Watson 1996, Watson \& Moritz 1997), are working to bring this knowledge to prospective and practising teachers. In this way advances made in education research are being translated into practice. Teaching and Learning about Decimals consists of background information about key mathematical ideas, case studies of children with common misconceptions about decimals, and teaching strategies, lesson plans, tests and games that challenge children's misconceptions about decimals.

\section{Key decisions made in design}

The following outlines some of the educational decisions made when designing the Teaching and Learning about Decimals resource. The underlying goal was to develop in our students the habit of thinking about children's thinking, in this resource specifically thinking about children's understanding of decimals, and then to apply appropriate teaching methods to challenge and remediate any misconceptions. Decimal numbers was chosen as a suitable domain because of the importance of the topic and the extent of children's misconceptions. Only about two thirds of Year 10 students fully understand decimal notation (Stacey \& Steinle, 1998). However, it is also used as a model domain, to teach the general importance of understanding children's thinking and selecting teaching activities that hone in on key ideas.

\section{Features of the resource}

Background Information There is rich background information about decimals, including the importance of decimals, the history of decimals and the metric measurement system, and decimals as a mathematical system. It is expected that most students will dip into this section, as a reference to clarify points about which they are uncertain (some of which will arise when the case studies prompt them to think more deeply) and to see the key ideas that need to be taught.

Case Studies Gaining an insight into children's thinking is facilitated through the case studies. Students develop an understanding of common misconceptions about decimal numbers and the ability to recognise misconceptions from patterns in children's responses to questions (for example, always choosing the longer decimal as the larger one) or through the language children use when talking about decimals (for example, saying 'hundreds' instead of 'hundredths'). There are six case studies in 
this resource that address some common misconceptions children have about decimals (see Stacey \& Steinle, 1998). For each case study there is: a brief overview of the misconception; a decimals comparison test ('select the largest number from a pair', see Figure 2) completed by the child with explanations available in pop up fields about why that choice would have been made by a child with that misconception; interviews with the child while undertaking a range of decimal activities where the child makes choices and explains her choices; a test for students to simulate the misconception to test their understanding of the misconception; teaching techniques for remediating each specific misconception; and links to current research in the area.

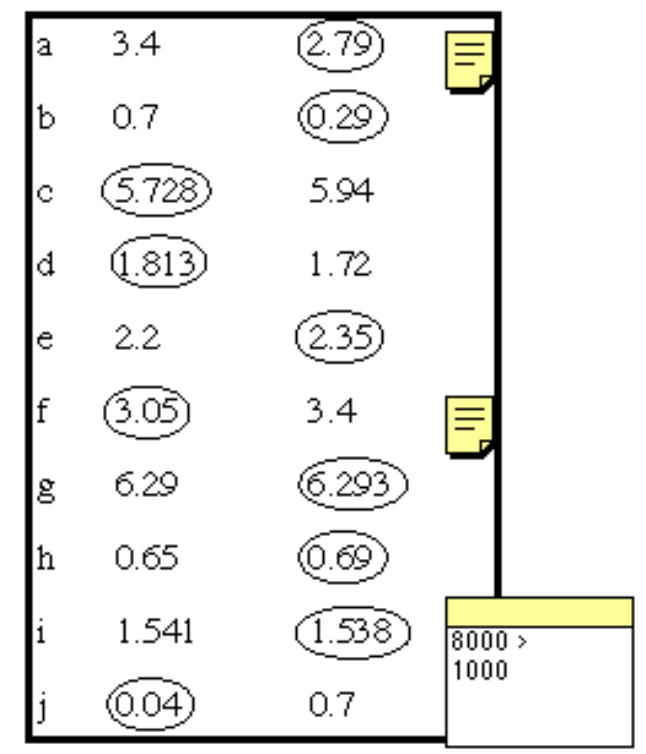

Figure 2: The completed test paper of a case study child. The instruction is to circle the larger number of each pair. The 'sticky notes' give an abbreviated report of what the case study child said about the answer.

The choice of using case studies as the way students develop an understanding about the misconceptions has been overwhelmingly successful. For each case study the misconception is identified with a specific child throughout the case. A photo of the child (child actors were used for images and voices), a name (pseudonym), and a child's voice is used in the case studies. This has led to students strongly identifying the misconceptions about decimals as 'real issues' that they will need to address when teachers, rather than mere 'textbook problems'. 
The interview dialogue was constructed for each case study from interview data collected in the associated research study. However, the dialogue has been edited in order to demonstrate ideas clearly, by amalgamating the most lucid explanations from a variety of real children with the same misconceptions, and deleting some parts of the real interviews that confuse rather than clarify the child's thinking. This means that the case studies present children's thinking more clearly than real children do. However, experience of teaching with this resource has supported this decision: our students need to become skilled in identifying misconceptions and working with the 'cleaned' cases is sufficiently challenging given their skill level and the limited time available in the university sessions.

Teaching Ideas Developing in our students the ability and habit of thinking about children's thinking is very desirable, but not enough! After diagnosing a misconception that a child has about decimals, students must then have access to a suite of teaching ideas that will challenge and remediate children's misconceptions. This section, with over 30 teaching activities, gives students a range of activities for their 'teaching tool box' when working with decimals.

\section{Feedback from students}

The following quotes were given by students during a review of mathematics education subjects, carried out by an external evaluator working on a Commonwealth funded project with no relationship to the authors of the resources. The students had used Teaching and Learning about Decimals in a course taken in either the previous year, or three years earlier, but they were not asked specifically about this resource. Thus, these comments were made spontaneously by the students when discussing their experiences in mathematics education, and reported to the authors by the external evaluator.

Last year we did something on the mistakes children make with decimals and I found that really useful and I have used that in a classroom setting helping children and being able to understand the different kinds of problems they have.

The work with the decimal package was very useful.

I agree that when we talked about different types of thinkers, that was the most useful thing in terms of dealing with different ability levels rather than actual strategies, it was recognising that one child might think this way about a problem whereas another might read it in a completely different way.

This feedback was very pleasing and further supports this approach to using rich multimedia resources to support teaching and learning. It 
demonstrates that these multimedia resources were one of the highlights of the mathematics education sequence.

\section{Ways it is used: Making children's thinking an object of study}

Using the 'Case Studies' section, our students engage in a range of modes of interactions with multimedia materials that challenge them to 'think like a teacher'. In this section there are six case studies of children with common misconceptions about decimals. For each case study there are examples of the child's work, such as a completed quiz about decimals (Figure 2), and interviews with the child where he or she is questioned as they undertake a range of tasks that explore their understanding of decimals. The interviews are available in a static version (images with text, suitable for printing and for students with modest computer facilities at home) and as QuickTime movies that have expert comments as subtitles. This range of resources within each case study gives our students practice in picking up clues about children's thinking about decimals.

The first task for our students is to diagnose the misconceptions of the case study children. Our students are challenged to deeply understand the misconceptions that children they will teach are likely to have by answering questions about decimals in the same way as the case study child would. It is important that our students come to understand the most common misconceptions so that they can diagnose them quickly in real students and can easily design teaching tasks that uncover them. The second task is to select from the resource some teaching activities that are targeted to address the difficulties that the case study child has. This is also a key task for teachers. It requires that the students, after having gained a deep understanding of the child's misconception, then engage deeply with a range of teaching activities that have been designed to address misconceptions about decimals. Students must link their understanding of the child's misconception about decimals with the specific aspects of decimals a particular teaching activity is addressing and then select appropriate teaching activities for a specific child. This is a challenging activity that demands of students deep engagement with children's thinking and with identifying the goals of a range of teaching activities

\section{Conclusions}

Children's thinking could not be easily studied in the past because it is a complex behavior producing minimal artifacts (usually written records) and can only be observed indirectly. One of the reasons why thinking is hard to study is that it is hard to capture. In recent years, as technology has progressed to tape recorders and video recorders, the research study of thinking has blossomed. Multimedia now has the potential to bring this 
into teacher education courses. This technology is enriching teacher education and is being used in the Virtual Classrooms and Teaching and Learning about Decimals multimedia resources. Multimedia can capture children's thinking and turn it into something that students can study. For this purpose multimedia derives its advantages from these features:

- A vast amount of information can be stored (needed because thinking is complex behavior).

- Examples can be stored in a catalogued form.

- Examples can be stored in an accessible form. Access for students can be vastly better than any other form of retrieval - from many places (home or university) and at any time.

By capturing episodes of thinking and enabling them to be well catalogued and easily accessed, multimedia can now provide a 'database' to be studied conveniently. Multimedia gives us the opportunity to create a collection of examples of thinking, which could revolutionise teacher education.

Although not a substitute for experience with children, resources such as these have distinct advantages as the scenarios presented have been distilled from research data and clearly illustrate representative case studies found in all classrooms. Our resources takes advantage of the careful analysis of selected interactions with children, to build awareness of well-documented, widespread features of children's thinking. In the classroom, teachers often have limited time to observe individual children's work and would therefore be greatly assisted if they were able to spot patterns in children's thinking. To do this, they must be very familiar with what they might expect to see. They need to gain this awareness in ways that supplement and build on their real life experiences. The children in the case studies (child actors with scripts) are very real to our students and this increases the level of engagement and makes the tasks authentic. This projects our students into their future roles as classroom teachers with the responsibility of understanding how a child is thinking about a task. Feedback from students is very positive and assignments on this material reflects a deeper thinking than had previously been apparent.

The multimedia resources that have been developed for undergraduate teacher education studies at the University of Melbourne allow our students to have experiences where they can see exemplary practice in a classroom or investigate how a child is thinking about decimal numbers. The development of multimedia is an expensive enterprise and we have been fortunate in receiving financial support from our University and from the Australian government for these projects. On the other hand, the choices of development modes (largely HTML and QuickTime video) and technological advances mean that keeping these multimedia resources up 
to date is now within the capabilities of our department and will require only relatively modest resources. (The technical aspects of these projects are discussed elsewhere, see Chambers \& Stacey, 1999). High initial costs of time and money make it highly desirable that multimedia resources are shared amongst universities. The relatively low cost of modification, however, means that the changing needs of several different courses can be accommodated, making sharing such resources feasible.

Our experience to date has been that multimedia has enhanced our teacher education courses. It enables complex behaviors to be captured and studied 'on demand' in the lecture room - be it the complex behavior of a class during a lesson or the complex thinking of a child puzzling over a problem. In this way, experience of the classroom can be built into every aspect of a teacher education program and shared as never before. The two projects highlight different ways that multimedia can be used to engage students actively with the multimedia and with the task.

\section{References}

Chambers, D.P. \& Dobbins, M. (1997). Computers and the K-6 Classroom: Kids Can Do! [CD] Department of Science and Mathematics Education, University of Melbourne.

Chambers, D.P. \& Stacey, K.C. (1999). Technically simple and educationally rich multimedia to support authentic tasks in teacher education. In G. Cumming, T. Okamoto \& L. Gomez (Eds), Advanced Research in Computers and Communication in Education. IOS Press, Netherlands Vol. 2, pp 457-464.

Stacey, K. \& Steinle, V. (1998). Refining the classification of students' interpretations of decimal notation. Hiroshima Journal of Mathematics Education, 6(March). 49-69.

Steinle, V., Stacey, K. \& Chambers, D. (2002). Teaching and Learning about Decimals. [CD] Department of Science and Mathematics Education, University of Melbourne. http:/ / extranet.edfac.unimelb.edu.au/DSME/decimals/

Mousley, J., Sullivan, P. \& Mousley, P. (1996). Learning About Teaching. Adelaide: Australian Association of Mathematics Teachers.

Watson, J.M. (1996). The CED PD CD. [CD] (Assisted by J.B. Moritz and S.Anderson) Hobart: DEETYA, AAMT Inc. and University of Tasmania.

Watson, J. \& Moritz, J. (1997). The C\&D PD CD: Professional development in chance and data in the technological age. In N. Scott \& H. Hollingsworth (Eds), Mathematics: Creating the Future. (pp 442-450) Adelaide: Australian Association of Mathematics Teachers.

Dianne P. Chambers and Kaye Stacey, Department of Science and Mathematics Education, The University of Melbourne, Australia. Email: d.chambers@unimelb.edu.au,k.stacey@unimelb.edu.au 